\title{
Lens assisted after Duplex mapping, Bridging technique of saphenous vein harvesting. (A new technique in saphenous vein harvesting, best substitute for endoscopic vein harvesting)
}

\author{
Ali Ali Mohamed Elbassioni* \\ Department of Adult Cardiac Surgery, Suez Canal University, Egypt
}

\begin{abstract}
Introduction: Ischemic heart disease is a common cause of death, which encourage is to find a definitive treatment for this disease. One of them is coronary artery bypass grafting. Still most commonly used graft is saphenous vein which harvested by different techniques.

Methodology and operative technique: we used lens assisted bridging technique after mapping preoperatively with duplex and compared it with traditional technique.

Results: After comparing the data obtained from both techniques we found that lens assisted, duplex mapping, bridging (LDB) technique had better overall results in comparison to conventional technique.

Conclusion: (LDB) technique can be a good substitute for endoscopic vein harvest especially in areas with low financial resources with results better than traditional open technique.
\end{abstract}

\section{Surgical background}

Coronary artery bypass grafting is one of most critical operations that need a very important care in each step. One of those steps is saphenous vein harvesting. Traditionally saphenous vein was harvested by traditional technique during which saphenous vein was harvested through long continuous skin incision. Then many trials have been done trying to reduce length of incision to achieve more cosmoses such as using Cusco-speculum, or using vein stripper or using Vega system (B/Braun-Aesculap, Tuttlingen, Germany) or SaphLITE system. All of them were searching for how to reach saphenous through smallest skin incision and main idea was creation of a lighted skin tunnel to allow good visualization of harvested vein to avoid vein injury. However, the main drawback was vein wall injury and minimal tears. So, we thought that using lenses assisted bridging technique (after preoperative US duplex mapping) will improve vein quality by enhancing vein visualization and good view for vein dissection by reaching side branches. After that we compared our results with that of conventional technique in terms of wound complications, pain, quality of vein harvested, time of harvesting, length of hospital stays and costs.

\section{Methodology}

Patient selection: (Who are the best candidates for this procedure?) All patients undergoing saphenous vein harvesting in multi-vessels disease coronary artery bypass grafting including both genders with matched age except patients with redo-CABG, patients who have severe varicosity, patients who will undergo emergent CABG, patients with systemic oedema due to liver and kidney and patients with skin diseases.

\section{Pre-operative preparation}

Every patient should have ultrasound mapping of long saphenous vein course with appropriate demarcation of site of large side branches which will be the site of desired skin incisions.

\section{Operative procedure}

Skin incision started at $4 \mathrm{~cm}$ above first area appeared to have side branches by US then multiple small incisions along saphenous vein course starting distally by plane of dissection along anterior surface of vein established usually $3 \mathrm{~cm}$ incision was given and a gap of 10 $\mathrm{cm}$. was left (interrupted segment). After that vein was dissected free from surrounding tissues by using surgical scissors and Langenbeck retractors under the guidance of 30-degree lens or 90-degree lens and its tributaries clipped on the patient side and cut then repeat process till desired length harvested.

\section{Intra-operative findings}

Saphenous vein grafts harvested by this technique assessed for vein quality, length of vein, length of skin incision, harvesting time, detection of bifurcated veins causing unnecessary skin incision and

Correspondence to: Ali Ali Mohamed Elbassioni, Assistant Lecturer of Adult Cardiac Surgery at Suez Canal University, Egypt, E-mail: alielbassionicts@ gmail.com/bessoo4uever@gmail.com

Key words: endoscopic vein harvesting, saphenous vein, traditional open technique Received: November 24, 2017; Accepted: December 19, 2017; Published: December 23, 2017 
Elbassioni AAM (2017) Lens assisted after Duplex mapping, Bridging technique of saphenous vein harvesting. (A new technique in saphenous vein harvesting, best substitute for endoscopic vein harvesting)

skin flap formation due to wrong skin incision course. See Figure 1 and Figure 2 below.

\section{Post-operative findings} weeks:

We will be assessed the following criteria during postoperative 6

1. Pain sensation.

2. Cosmetic results.

3. Patient satisfaction.

4. Lower limb oedema.

5. Duration of Post-operative hospital stay.

6. Wound complications assessment.

\section{Results}

Our results showed that in conventional technique length of incision was longer, little better vein integrity and quality but significant level flap formation and sudden detection of bifurcated narrow vein during procedure which is not candidate to be a good graft, while on the other hand bridging technique showed shorter vein with slightly lower quality and no skin flap formation or incision over bifurcated vein. See Table 1.

\section{Discussion}

\section{Intraoperative findings}

During this study we found that (LDB) technique was associated with good vein quality with accepted vein length and no skin flap was

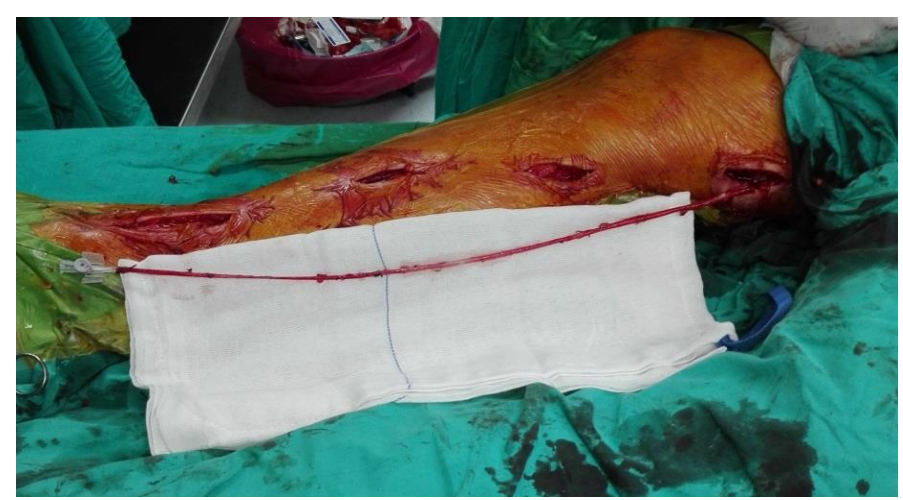

Figure 1. Showing lens assisted saphenous vein harvesting technique with small skin bridges with a good vein quality .

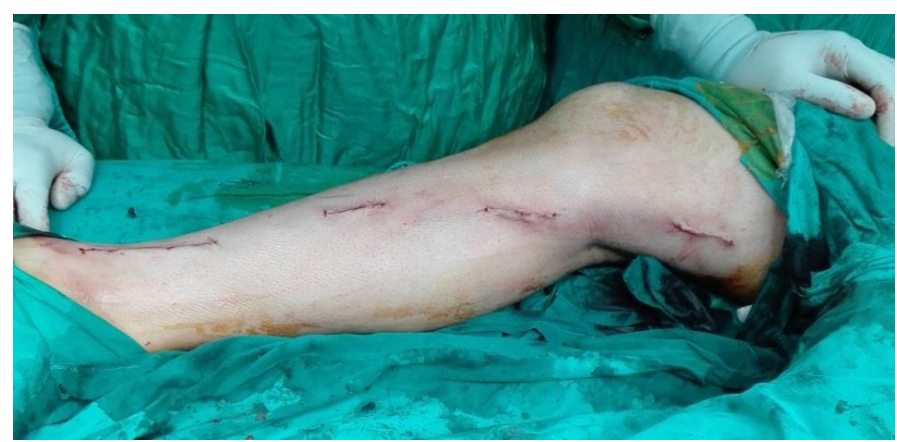

Figure 2. Showing a long saphenous vein harvested by lens assisted bridging technique with good cosmetic results.
Table 1. Show comparison between traditional and LDB technique regarding vein quality, vein length, skin flap formation and bad quality vein detection.

\begin{tabular}{|c|c|c|c|c|}
\hline & Conventional & Bridging & P-value & Significance \\
\hline Length of incision & Mean: $31.7 \mathrm{~cm}$ & Mean: $12 \mathrm{~cm}$ & 0 & Significant \\
\hline Vein harvesting time & Mean: $37.6 \mathrm{~min}$ & Mean: $38 \mathrm{~min}$ & 0.865 & Not significant \\
\hline \multirow{4}{*}{$\begin{array}{l}\text { Vein integrity (No. of } \\
\text { repairs for tears sand } \\
\text { side holes) }\end{array}$} & No repairs: 18 & No repairs: 16 & \multirow{4}{*}{0.723} & \multirow{4}{*}{ Not significan } \\
\hline & 1 repair: 6 & 1 repair: 8 & & \\
\hline & 2 repairs: 4 & 2 repairs: 2 & & \\
\hline & $>2$ repairs: 2 & $>2$ repairs: 4 & & \\
\hline \multirow{3}{*}{ Vein quality } & Good: 20 & Good: 16 & \multirow{3}{*}{0.533} & \multirow{3}{*}{ Not significan } \\
\hline & Fair: 8 & Fair: 12 & & \\
\hline & Bad: 2 & Bad: 2 & & \\
\hline Skin flap formation & $50 \%$ of patients & $0 \%$ of patients & 0.003 & Significant \\
\hline $\begin{array}{c}\text { Skin incision over } \\
\text { bifurcated useless vein }\end{array}$ & $40 \%$ of patients & $0 \%$ of patients & 0.004 & Significant \\
\hline
\end{tabular}

formed as duplex mapping helped us to identify course of saphenous vein well also duplex mapping helped us to detect bifurcated narrow veins preoperatively so we didn't discover it intraoperatively as in traditional technique.

Duplex mapping was described by Alan Soo et al. in previous study which inspired me to use duplex in bridging technique [1].

\section{Postoperative findings}

During this we found our technique with lower rate of wound complications even more than traditional tunnelling method as there were lower wound complications in comparison to the traditional methods [2]. Also, it was found less hematoma, discharge and ecchymosis [3].

In addition to above I realized that this method has more patient satisfaction and lower costs as no more tools were used [4]. Finally, it's important to mention that this technique had the same harvesting time as traditional technique. [5].

\section{Conclusion}

In conclusion, lens assisted, duplex mapping, bridging technique is a new technique that gives us a better substitute than conventional technique or even better than endoscopic vein harvesting as it is cost effective.

\section{References}

1. Soo A, Noel D, MacGowan S (2013) Ultrasound mapping of the long saphenous vein in coronary artery bypass graft surgery. Interact Cardiovasc Thorac Surg 16: 886-887. [Crossref]

2. Athanasiou T, Aziz O, Al-Ruzzeh S, Philippidis P, Jones C, et al. (2004) Are wound healing disturbances and length of hospital stay reduced with minimally invasive vein harvest? A meta-analysis. Eur J Cardiothorac Surg 26: 1015-1026. [Crossref]

3. Hijazi K, Emad M (2010) Comparative study of traditional long incision vein harvesting and multiple incisions with small skin bridges in patients with coronary artery bypass grafting at King Abdullah University Hospital-Jordan. Revista Brasileira De Cirurgia Cardiovascular 25: 197-201. [Crossref]

4. Khan H, Ursalan A, Najam O, Waterworth P, Fildes JE, et al. (2010) A comparative analysis of saphenous vein conduit harvesting techniques for coronary artery bypass grafting-standard bridging versus the open technique. Interact Cardiovasc Thorac Surg 10: 27-31. [Crossref]

5. Musharaf M, Muhammad A (2013) Interrupted Vein Harvesting Technique with Skin Bridges Leads to Decrease Incidence of Leg Wound Infection as Compared to Open Long Incision Vein Harvesting Technique in Patients with Coronary Artery Bypass Grafting. PJC 24: 467-657.

Copyright: (C2017 Elbassioni AAM. This is an open-access article distributed under the terms of the Creative Commons Attribution License, which permits unrestricted use, distribution, and reproduction in any medium, provided the original author and source are credited. 